Article

\title{
Novel Enantiopure Sigma Receptor Modulators: Quick (Semi-)Preparative Chiral Resolution via HPLC and Absolute Configuration Assignment
}

\author{
Marta Rui ${ }^{1,2}$, Annamaria Marra ${ }^{1}$, Vittorio Pace ${ }^{2}$, Markus Juza ${ }^{3}$, Daniela Rossi ${ }^{1}$ \\ and Simona Collina ${ }^{1, *}$ \\ 1 Department of Drug Sciences, Medicinal Chemistry and Pharmaceutical Technology Section, \\ University of Pavia, Viale Taramelli 12, Pavia 27100, Italy; marta.rui01@universitadipavia.it (M.R.); \\ annamaria.marra@unipv.it (A.M.); daniela.rossi@unipv.it (D.R.) \\ 2 Department of Pharmaceutical Chemistry, University of Vienna, Althanstrasse 14, Vienna 1090, Austria; \\ vittorio.pace@univie.ac.at \\ 3 Corden Pharma Switzerland LLC, Eichenweg 1, Liestal 4410, Switzerland; markus.juza@cordenpharma.com \\ * Correspondence: simona.collina@unipv.it; Tel.: +39-0382-987-379 \\ Academic Editors: Claudio Villani and Derek J. McPhee \\ Received: 20 July 2016; Accepted: 6 September 2016; Published: 10 September 2016
}

\begin{abstract}
The identification of novel pan-sigma receptor (SR) modulators, potentially useful in cancer treatment, represents a new goal of our research. Here, we report on the preparation of novel chiral compounds characterized by a 3-C alkyl chain bridging an aromatic portion to a 4-benzyl-piperidine moiety. All of the studied compounds have been prepared both in racemic and enantiomerically-pure form, with the final aim to address the role of chirality in the SR interaction. To isolate and characterize enantiomeric compounds, high-performance liquid chromatography (HPLC) procedures were set up. A systematic analytical screening, involving several combinations of chiral stationary and mobile phases, allowed us to optimize the analytical resolution and to set up the (semi-)preparative chromatographic conditions. Applying the optimized procedure, the enantiomeric resolution of the studied compounds was successfully achieved, obtaining all of the compounds with an enantiomeric excess higher than 95\%. Lastly, the absolute configuration has been empirically assigned to enantiopure compounds, combining the electronic circular dichroism (ECD) technique to the elution order study.
\end{abstract}

Keywords: sigma receptor (SR) modulators; amylose- and cellulose-derived CSPs; chiral resolution; enantioselective HPLC; electronic circular dichroism (ECD)

\section{Introduction}

Sigma receptors (SRs) are involved in different pharmacological and pathological pathways. They modulate cell survival and excitability and sub-serve many critical functions in the human body. To date, two subtypes have been identified: Sigma 1 (S1R) and Sigma 2 receptors (S2R). S1Rs are overexpressed in the central nervous system (CNS), while S2Rs are overexpressed in tumor cells and tissues in proliferation [1]. Accordingly, S1R modulators could be useful for the treatment of several CNS diseases, such as anxiety, depression, schizophrenia, drug addiction, Parkinson's and Alzheimer's diseases [2], whereas S2R ligands could have a relevant role in cancer diagnosis and therapy [3]. Since some research groups identified an overexpression of S1R in different typologies of cancer cells and demonstrated a strict correlation between S1R and this pathological manifestation, S1R has been also proposed as a potential target for treating cancer conditions [4-6]. As a result, therapies that have S1R and S2R as targets might play a role against a wide spectrum of cancer types. Indeed, recent literature highlights the anticancer potential of ligands able to bind both receptor subtypes, 
called pan-SR ligands [7]. The work presented here falls into this field, and it is a part of our ongoing research focused on the identification of novel SR modulators. Along the years, we prepared and studied a wide compound library of SR modulators [8]. The SAR analysis evidenced that a good affinity towards both SRs is related to the presence of a bulky aminic moiety $[9,10]$. Particularly, the 4-benzylpiperidine derivative RC-106 (Figure 1) is characterized by a good affinity toward both S1R and S2R (Ki S1R $=12.0 \mathrm{nM} \pm 6.0 ; \mathrm{Ki} \mathrm{S} 2 \mathrm{R}=22.0 \mathrm{nM} \pm 1.1$ ). Moreover, the SAR studies of chiral SR modulators showed that small changes in the ligand structure markedly influence the ability of SRs to discriminate the enantiomeric form. For example, racemic and enantiomeric RC-33 (Figure 1) interact in a non-stereoselective manner with SRs, both enantiomers showing a similar affinity toward both S1R and S2R [11-13]. A different behavior was observed for the analogue RC-34, characterized by the presence of an electronegative element (the only structural difference with respect to RC-33). In this case, the (S)-configured enantiomer resulted in being the eutomer, with the following eudismic ratio $\left(E R, K_{i}\right.$ distomer $/ K_{i}$ eutomer $): E R_{S 1 R}=8.3$ and $E_{S 2 R}=2.5$ [14]. According to these results, the capability of SRs to discriminate between the enantiomers of a ligand seems to be strictly related to its structural features [15].
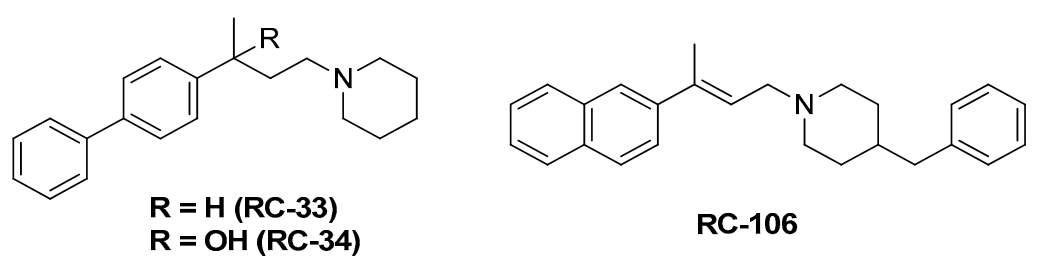

Figure 1. Structures of RC-33, RC-34 and RC-106.

In this paper, we report on the preparation of the potential chiral SR modulators 1-6, characterized by an alkyl or alcoholic spacer bridging an aromatic moiety to the 4-benzyl-piperidine portion (Table 1) and discuss in detail our efforts to develop easy-to-use chiral chromatographic methods, this approach being effective for both analytical and preparative purposes [16-19]. Moreover, we report on absolute configuration assignment studies of enantiomerically-pure 1-6, combining electronic circular dichroism (ECD) and elution order studies. Our final aim is to have enantiopure 1-6 in a sufficient amount for the biological investigation, in order to study the intriguing aspect of the influence of chirality in SR interaction.

Table 1. Molecules under investigation.

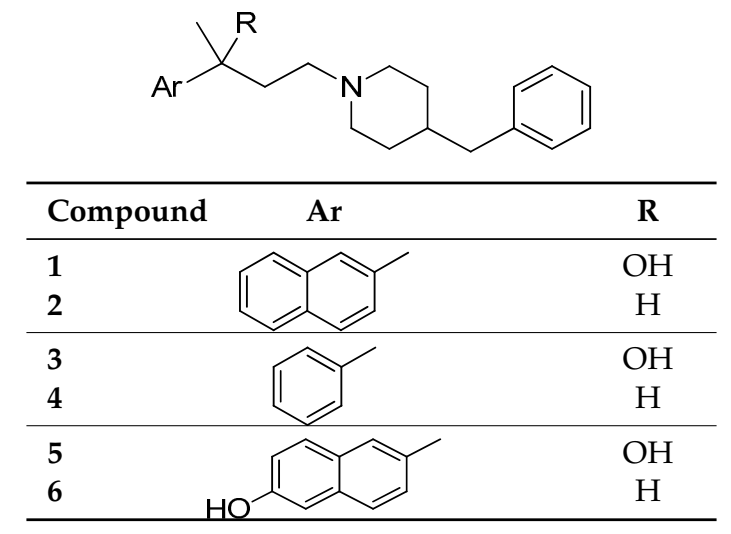

\section{Results and Discussion}

\subsection{Synthesis}

As reported in Scheme 1, the synthesis of 4-(4-benzyl-piperidin-1-yl)-butan-2-one, common intermediate (A), was accomplished in a good yield via the Michael addition of 4-benzyl piperidine to 
but-3-en-2-one in absolute ethanol and glacial acetic acid. Briefly, Compounds $\mathbf{1}$ and $\mathbf{3}$ were obtained adopting a nucleophilic addition strategy of in situ-generated organolithium species to ketones. The appropriate aryl-bromine was lithiated with an excess of tert-butyllithium $(t$-BuLi) in anhydrous diethyl ether $\left(\mathrm{Et}_{2} \mathrm{O}\right)$ at $-78^{\circ} \mathrm{C}$, followed by the addition of $\mathbf{A}$ : the desired tertiary alcohols $\mathbf{1}$ and $\mathbf{3}$ were obtained in practical yields. Subsequently, the so-obtained alcohols were subjected to dehydration with trifluoroacetic anhydride under copper(I) triflate catalytic conditions [20]. Purification on alumina column chromatography provided the olefins $\mathbf{2 a}$ and $\mathbf{4 a}$, which were hydrogenated $(\mathrm{Pd}(0) / \mathrm{C} 10 \%$ $(p / p))$ to give the corresponding reduced amines 2 and 4 . The same tactic was applied for accessing naphthol derivatives 5 and $\mathbf{6}$. However, prior to lithiation, the protection of the aromatic alcohol as TBS-ether was required to prevent interference during the metalation step. Additional points merit mention: (1) keeping the temperature at $-50{ }^{\circ} \mathrm{C}$ after the quenching with $\mathbf{A},(2)$ employing THF as the solvent and (3) using the less basic n-BuLi as the lithiating agent resulted in being beneficial to maximize the yield. Lastly, under identical conditions to those ones reported for the synthesis of 2 and 4, Compound 6 was obtained in a good yield.

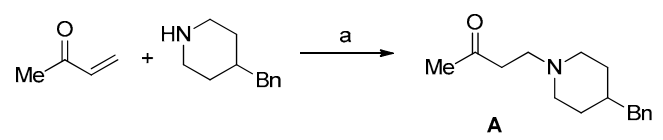

Synthesis of $\beta$-Aminoketone A

Synthesis of Compounds 1.4

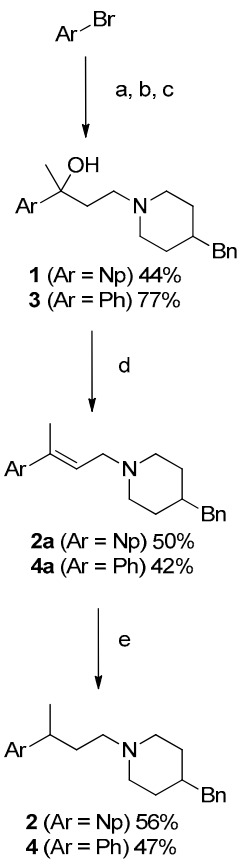

Synthesis of Compounds 5-6<smiles>Oc1ccc2cc(Br)ccc2c1</smiles><smiles>CC(C)(C)Oc1ccc2cc(C(C)(O)CCN3CCC(Br)CC3)ccc2c1</smiles><smiles>CC(C)(O)c1ccc2cc(O)ccc2c1</smiles><smiles>C/C(=C\CN1CCC(Cc2ccccc2)CC1)c1ccc2cc(OCC(C)C)ccc2c1</smiles>

g

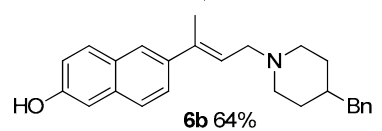

h

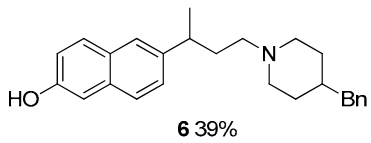

Scheme 1. Synthesis of Compounds 1-6. Experimental conditions: $\beta$-aminoketone A: (a) glacial acetic acid, abs EtOH, rt; Compounds 1-4: (a) $t$-BuLi, anhydrous $\mathrm{Et}_{2} \mathrm{O},-78{ }^{\circ} \mathrm{C}$ to $\mathrm{rt}$; (b) ketone $\mathbf{A},-78{ }^{\circ} \mathrm{C}$ to $0{ }^{\circ} \mathrm{C}$; (c) $\mathrm{H}_{2} \mathrm{O} \mathrm{rt}$; (d) $\mathrm{Cu}(\mathrm{OTf})_{2},\left(\mathrm{CF}_{3} \mathrm{O}\right)_{2} \mathrm{O}$, anhydrous DCM, $0{ }^{\circ} \mathrm{C}$ to rt; $(\mathbf{e}) \mathrm{H}_{2}, \mathrm{Pd}(0) / \mathrm{C} 10 \%(p / p)$, abs EtOH, rt; Compounds 5-6: (a) TBDMSCl, DMF; (b) $n$-BuLi, THF, $-78{ }^{\circ} \mathrm{C}$; (c) ketone $\mathbf{A},-50{ }^{\circ} \mathrm{C}$; (d) $\mathrm{NH}_{4} \mathrm{Cl}$ (aq.), rt; (e) TBAF, $\mathrm{CH}_{2} \mathrm{Cl}_{2}, 0{ }^{\circ} \mathrm{C}$; (f) TFAA, $\mathrm{Cu}(\mathrm{OTf})_{2}\left(2 \mathrm{~mol} \%\right.$ ) $\mathrm{CH}_{2} \mathrm{Cl}_{2}, 0^{\circ} \mathrm{C}$ to rt; (g) TBAF, $\mathrm{CH}_{2} \mathrm{Cl}_{2} ;$ (h) $\mathrm{H}_{2}$ (1 atm) $\mathrm{Pd} / \mathrm{C}(10 \mathrm{~mol} \%) \mathrm{EtOH}$, rt. 


\subsection{Analytical Screening and Development of a Scalable Resolution Method}

The strategy we adopted for obtaining enantiopure 1-6 is based on our knowledge and extensive experience in chiral liquid chromatography that led us to have a wide range of chiral analytical and (semi-)preparative columns in-house. As a first choice, we used amylose- and cellulose-based CSPs immobilized on silica gel chiral columns, due to their wide solvent compatibility, versatility and robustness. In details, Chiralpak IC (cellulose tris(3,5-dichlorophenylcarbamate immobilized on silica gel) and Chiralpak IA (amylose tris(3,5-dimethylphenylcarbamate, immobilized on silica gel) have been used, eluting with alcohols $(\mathrm{MeOH}$ or/and $\mathrm{EtOH})$ or with $n$-hep in the presence of polar modifiers (EtOH or IPA), DEA $0.1 \%$ and TFA $0.3 \%$.

Therefore, the HPLC screening protocol of Table 2 was applied, and only when the results of this screening were encouraging, but not fully successful, the mobile phase was slightly modified in order to achieve a compound baseline separation. Since no satisfactory chiral separation for all compounds was obtained, conventional cellulose-based chiral column Chiralcel OJ-H (cellulose tris(4-methylbenzoate, coated on silica gel) was also experimented with, again eluting with alcohols (MeOH or/and EtOH) or $n$-hep in the presence of IPA as polar modifier and adding DEA $0.1 \%$. Results of the analytical screening are reported in Tables 3-5 and are expressed as retention $(k)$, selectivity $(\alpha)$ and resolution (Rs) factors.

Table 2. Screening protocol: mobile phase composition.

\begin{tabular}{ccccc}
\hline \multirow{2}{*}{ Entry } & \multicolumn{4}{c}{ Mobile Phase Composition (\%) } \\
\cline { 2 - 5 } & MeOH & EtOH & $n$-hep & IPA \\
\hline 1 & 100 & - & - & - \\
2 & 50 & 50 & - & - \\
3 & - & 10 & 90 & - \\
4 & - & - & 90 & 10 \\
\hline
\end{tabular}

Chiralpak IC provided a baseline separation of Compounds 1, 2, 4 and 6, even if the chromatographic conditions were not suitable for a productive scale-up (Table 3). In detail, no enantioresolution was observed eluting with alcohols (data not shown), while modest or good values of $\alpha$ and Rs were obtained eluting with $n$-hep/EtOH or $n$-hep/IPA, even if the retention times $\left(t_{R}\right)$ are quite long ( $t_{R}$ of the second eluted enantiomer ranging from 30-90 min). Moreover, to solve Compound 1, a slight modification of the mobile phase composition of the screening protocol, eluting with $n$-hep/IPA $(92 / 8, v / v)$, has been necessary. Nevertheless, a modest resolution was achieved $(\alpha=1.12$ and $\mathrm{Rs}=1.44)$.

Table 3. Analytical screening on Chiralpak IC with different mobile phases containing $0.1 \%$ DEA and $0.3 \%$ TFA.

\begin{tabular}{|c|c|c|c|c|c|c|c|c|}
\hline \multirow{2}{*}{ Compound } & \multicolumn{3}{|c|}{ Mobile Phase } & \multirow{2}{*}{$\mathbf{K}_{1}$} & & \multirow{2}{*}{$\mathbf{K}_{2}$} & \multirow{2}{*}{ A } & \multirow{2}{*}{ Rs } \\
\hline & $n$-hep (\%) & EtOH (\%) & IPA (\%) & & & & & \\
\hline \multirow{3}{*}{$(R / S)-\mathbf{1}$} & 90 & 10 & - & \multirow{2}{*}{\multicolumn{3}{|c|}{$\begin{array}{l}1.52 \\
4.45\end{array}$}} & 1 & - \\
\hline & 90 & - & 10 & & & & 1 & - \\
\hline & 92 & - & 8 & 7.76 & & 8.72 & 1.12 & 1.44 \\
\hline \multirow{2}{*}{$(R / S)-\mathbf{2}$} & 90 & 10 & - & \multirow{2}{*}{\multicolumn{2}{|c|}{1.93}} & & 1 & - \\
\hline & 90 & - & 10 & & & 9.62 & 1.23 & 2.36 \\
\hline \multirow{2}{*}{$(R / S)-\mathbf{3}$} & 90 & 10 & - & \multirow{2}{*}{\multicolumn{3}{|c|}{$\begin{array}{l}1.29 \\
1.35\end{array}$}} & 1 & - \\
\hline & 90 & - & 10 & & & & 1 & - \\
\hline \multirow{2}{*}{$(R / S)-\mathbf{4}$} & 90 & 10 & - & \multicolumn{3}{|c|}{1.56} & 1 & - \\
\hline & 90 & - & 10 & 6.52 & & 8.68 & 1.33 & 3.08 \\
\hline \multirow{2}{*}{$(R / S)-\mathbf{5}$} & 90 & 10 & - & \multirow{2}{*}{\multicolumn{3}{|c|}{$\begin{array}{c}3.24 \\
15.79\end{array}$}} & 1 & - \\
\hline & 90 & - & 10 & & & & 1 & - \\
\hline \multirow{2}{*}{$(R / S)-6$} & 90 & 10 & - & \multirow{2}{*}{\multicolumn{2}{|c|}{4.07}} & & 1 & - \\
\hline & 90 & - & 10 & & & 29.97 & 1.11 & 1.26 \\
\hline
\end{tabular}


Chiralpak IA gave rise to better results, being effective in resolving Compounds 1-6 (Table 4). Interestingly, the presence of $n$-hep in the mobile phase was essential for the separation of 1, 3 and 5 and gave rise to quite long retention times ( $t_{R}$ of the second eluted enantiomer ranging from 15-65 min). Conversely, 2, 4 and 6 (endowed with an alkyl spacer) have been successfully resolved eluting with pure $\mathrm{MeOH}$ in short times ( $t_{\mathrm{R}}$ second eluted enantiomer less than $10 \mathrm{~min}$ ).

Table 4. Analytical screening on Chiralpak IA with different mobile phases containing $0.1 \%$ DEA.

\begin{tabular}{|c|c|c|c|c|c|c|c|c|}
\hline \multirow{2}{*}{ Compound } & \multicolumn{4}{|c|}{ Mobile Phase } & \multirow{2}{*}{$\mathbf{K}_{\mathbf{1}}$} & \multirow{2}{*}{$\mathbf{K}_{2}$} & \multirow{2}{*}{$\alpha$} & \multirow{2}{*}{ Rs } \\
\hline & $n$-hep (\%) & MeOH (\%) & EtOH (\%) & IPA (\%) & & & & \\
\hline \multirow{3}{*}{$(R / S)-\mathbf{1}$} & - & 100 & - & - & \multicolumn{2}{|c|}{5.48} & 1 & - \\
\hline & 90 & - & 10 & - & \multicolumn{2}{|c|}{3.48} & 1 & - \\
\hline & 90 & - & - & 10 & 5.00 & 5.55 & 1.11 & 1.69 \\
\hline \multirow{3}{*}{$(R / S)-\mathbf{2}$} & - & 100 & - & - & 1.00 & 1.24 & 1.24 & 1.73 \\
\hline & 90 & - & 10 & - & \multicolumn{2}{|c|}{2.62} & 1 & - \\
\hline & 90 & - & - & 10 & 4.24 & 5.07 & 1.19 & 2.08 \\
\hline \multirow{3}{*}{$(R / S)-\mathbf{3}$} & - & 100 & - & - & \multicolumn{2}{|c|}{0.53} & 1 & - \\
\hline & 90 & - & 10 & - & 2.77 & 3.25 & 1.17 & 1.67 \\
\hline & 90 & - & - & 10 & \multicolumn{2}{|c|}{3.84} & 1 & - \\
\hline \multirow{3}{*}{$(R / S)-4$} & - & 100 & - & - & 0.57 & 0.81 & 1.42 & 3.06 \\
\hline & 90 & - & 10 & - & \multicolumn{2}{|c|}{1.99} & 1 & - \\
\hline & 90 & - & - & 10 & \multicolumn{2}{|c|}{3.21} & 1 & - \\
\hline \multirow{3}{*}{$(R / S)-\mathbf{5}$} & - & 100 & - & - & \multicolumn{2}{|c|}{0.35} & 1 & - \\
\hline & 90 & - & 10 & - & 13.72 & 17.38 & 1.27 & 3.04 \\
\hline & 90 & - & - & 10 & 14.68 & 18.55 & 1.26 & 2.95 \\
\hline \multirow{3}{*}{$(R / S)-6$} & - & 100 & - & - & 0.96 & 1.27 & 1.32 & 2.49 \\
\hline & 90 & - & 10 & - & 8.90 & 10.45 & 1.18 & 3.22 \\
\hline & 90 & - & - & 10 & 19.76 & 23.86 & 1.21 & 2.94 \\
\hline
\end{tabular}

Flow rate: $1 \mathrm{~mL} / \mathrm{min}$. Detection: $254 \mathrm{~nm}$ (Compounds 1, 2, 5, 6) and $220 \mathrm{~nm}$ (Compounds 3, 4).

On the basis of these results and keeping in mind that our purpose is to set up an economic and productive preparative enantiomer separation for 1-6, we turned our attention to a further analytical screening, using the Chiralcel OJ-H column. Baseline separation of Compounds 1-3 and $\mathbf{5}$ has been obtained in short retention times, less than $12 \mathrm{~min}$ (referred to the second eluted enantiomer). Results are reported in Table 5. Interestingly, high enantioselectivity and good resolution have been achieved eluting only with alcohols, while no separation occurs eluting with $n$-hep, with the only exception of Compound $\mathbf{1 .}$

Table 5. Analytical screening on Chiralcel OJ-H with different mobile phases containing $0.1 \%$ DEA.

\begin{tabular}{|c|c|c|c|c|c|c|c|c|}
\hline \multirow{2}{*}{ Compound } & \multicolumn{4}{|c|}{ Mobile Phase } & \multirow{2}{*}{$K_{1}$} & \multirow{2}{*}{$K_{2}$} & \multirow{2}{*}{$\alpha$} & \multirow{2}{*}{ Rs } \\
\hline & $n$-hep (\%) & MeOH (\%) & EtOH (\%) & IPA (\%) & & & & \\
\hline \multirow{4}{*}{$(R / S)-\mathbf{1}$} & - & 100 & - & - & \multicolumn{2}{|c|}{2.5} & 1 & - \\
\hline & - & 50 & 50 & - & 1.77 & 2.40 & 1.36 & 3.14 \\
\hline & - & - & 100 & - & 1.03 & 1.63 & 1.58 & 3.25 \\
\hline & 90 & - & - & 10 & 1.56 & 2.27 & 1.46 & 2.35 \\
\hline \multirow{4}{*}{$(R / S)-\mathbf{2}$} & - & 100 & - & - & 3.98 & 4.80 & 1.21 & 2.46 \\
\hline & - & 50 & 50 & - & 1.87 & 2.25 & 1.20 & 1.97 \\
\hline & - & - & 100 & - & 1.23 & 1.46 & 1.19 & 1.83 \\
\hline & 90 & - & - & 10 & \multicolumn{2}{|c|}{9.61} & 1 & - \\
\hline
\end{tabular}


Table 5. Cont.

\begin{tabular}{|c|c|c|c|c|c|c|c|c|}
\hline \multirow{2}{*}{ Compound } & \multicolumn{4}{|c|}{ Mobile Phase } & \multirow{2}{*}{$K_{1}$} & \multirow{2}{*}{$K_{2}$} & \multirow{2}{*}{$\alpha$} & \multirow{2}{*}{ Rs } \\
\hline & $n$-hep (\%) & MeOH (\%) & EtOH (\%) & IPA (\%) & & & & \\
\hline \multirow{4}{*}{$(R / S)-\mathbf{3}$} & - & 100 & - & - & 1.24 & 1.80 & 1.45 & 4.05 \\
\hline & - & 50 & 50 & - & 0.70 & 0.93 & 1.33 & 2.32 \\
\hline & - & - & 100 & - & \multicolumn{2}{|c|}{2.24} & 1 & - \\
\hline & 90 & - & - & 10 & \multicolumn{2}{|c|}{0.46} & 1 & - \\
\hline \multirow{4}{*}{$(R / S)-\mathbf{4}$} & - & 100 & - & - & \multicolumn{2}{|c|}{1.52} & 1 & - \\
\hline & - & 50 & 50 & - & \multicolumn{2}{|c|}{0.74} & 1 & - \\
\hline & - & - & 100 & - & \multicolumn{2}{|c|}{0.46} & 1 & - \\
\hline & 90 & - & - & 10 & \multicolumn{2}{|c|}{0.54} & 1 & - \\
\hline \multirow{4}{*}{$(R / S)-\mathbf{5}$} & - & 100 & - & - & 1.10 & 1.61 & 1.46 & 2.62 \\
\hline & - & 50 & 50 & - & 0.74 & 1.07 & 1.45 & 1.99 \\
\hline & - & - & 100 & - & 0.39 & 0.70 & 1.79 & 1.92 \\
\hline & 90 & - & - & 10 & \multicolumn{2}{|c|}{0.32} & 1 & - \\
\hline \multirow{4}{*}{$(R / S)-6$} & - & 100 & - & - & \multicolumn{2}{|c|}{2.20} & 1 & - \\
\hline & - & 50 & 50 & - & \multicolumn{2}{|c|}{1.25} & 1 & - \\
\hline & - & - & 100 & - & \multicolumn{2}{|c|}{0.73} & 1 & - \\
\hline & 90 & - & - & 10 & \multicolumn{2}{|c|}{0.61} & 1 & - \\
\hline
\end{tabular}

Flow rate: $0.5 \mathrm{~mL} / \mathrm{min}$. Detection: $254 \mathrm{~nm}$ (Compounds 1, 2, 5, 6) and $220 \mathrm{~nm}$ (Compounds 3, 4).

To sum up, we set up methods able to give baseline separation of 1-6 in a relatively short analysis time. In detail, the methods foresee the use of Chiralpak IA for solving Compounds $\mathbf{4}$ and $\mathbf{6}$ and of Chiralcel OJ-H for solving 1-3 and 5. In view of these results, we considered the developed methodologies suitable for the scale-up to the (semi-)preparative scale, and accordingly, no further attempts were made to extend the screening under HPLC conditions. Figure 2 shows chromatograms of racemic 1-6, when the highest resolution was reached, that is using Chiralpak IA or Chiralcel OJ-H columns, eluting with $100 \%$ methanol (Compounds 2-6) or with $100 \%$ ethanol (Compound 1).
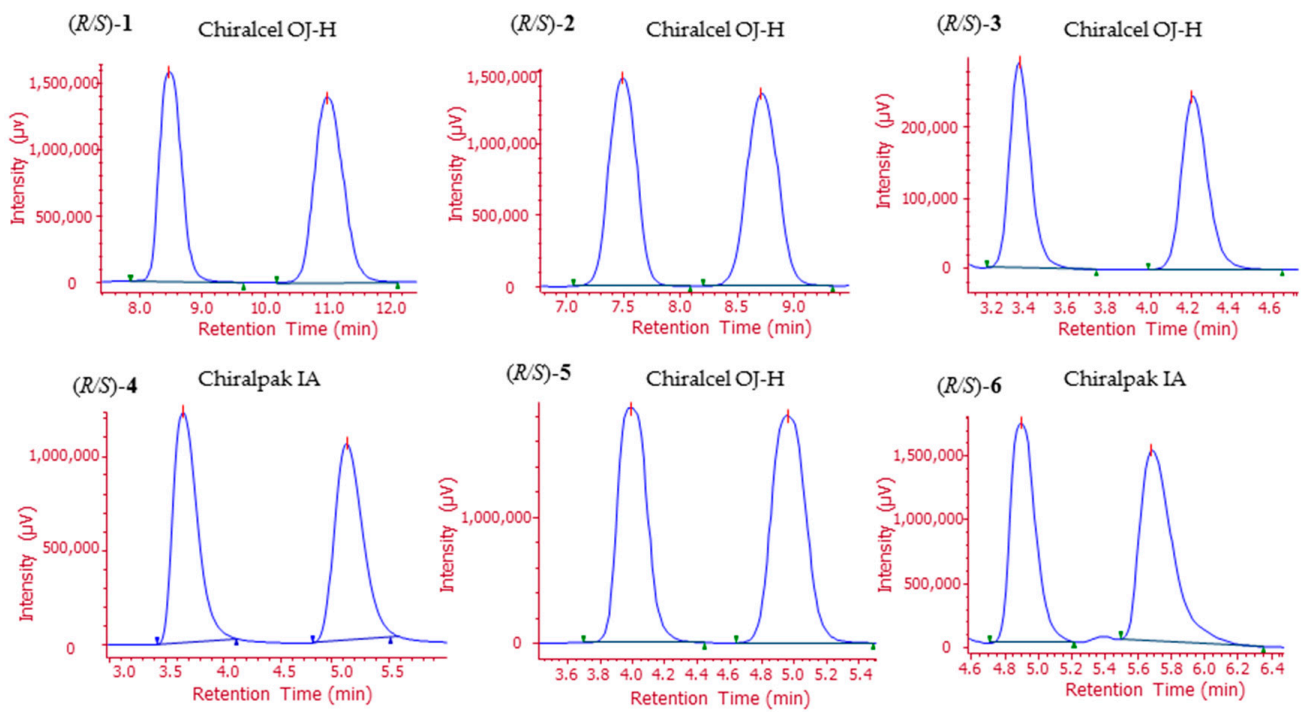

Figure 2. Analytical enantiomer separation of $(R / S)-\mathbf{1},(R / S)-\mathbf{2},(R / S)-\mathbf{3},(R / S)-\mathbf{5}$ on Chiralcel OJ-H $(4.6 \mathrm{~mm} \times 150 \mathrm{~mm}, \mathrm{dp}=5 \mu \mathrm{m})$ and of $(R / S)-4$ and $(R / S)-6$ on Chiralpak IA $(4.6 \mathrm{~mm} \times 250 \mathrm{~mm}$, $\mathrm{dp}=5 \mu \mathrm{m}) .(R / S)-\mathbf{1}$ elution condition: $100 \% \mathrm{EtOH}$, DEA $0.1 \%$, flow rate $0.5 \mathrm{~mL} / \mathrm{min}$. $(R / S)-2,(R / S)-3$ and $(R / S)$-5 elution condition: $100 \% \mathrm{MeOH}$, DEA $0.1 \%$, flow rate $1.0 \mathrm{~mL} / \mathrm{min}$. $(R / S)-4$ and $(R / S)-6$ elution condition: $100 \% \mathrm{MeOH}, 0.1 \% \mathrm{DEA}$, flow rate $1 \mathrm{~mL} / \mathrm{min}$. For all: injection volume $10 \mu \mathrm{L}$. 


\subsection{Preparation of Enantiomeric 1-6 through HPLC}

During the drug discovery process, (semi-)preparative resolution of enantiomers using HPLC is a powerful technique for the rapid preparation of enantiomers. Employing this technique, important prerequisites for an economic and productive preparative enantiomer separation are: (i) retention times as short as possible; (ii) high solubility of the racemate and the enantiomers in the eluent/injection solvent; and (iii) the use of a mobile phase consisting of a pure low-cost solvent, facilitating work-up and re-use of the mobile phase. As previously discussed, using Chiralpak IA or Chiralcel OJ-H columns and eluting with alcohols added with DEA (0.1\%), relatively short retention times (less than 12 min for the second eluted enantiomer), high enantioselectivity and good resolution could be observed (Figure 2). Accordingly, these experimental conditions were transferred to a Chiralpak IA and a Chiralcel OJ-H columns with an ID of $10 \mathrm{~mm}$, on which a maximum of $12.5 \mathrm{mg}$ could be separated in one run, depending on the solubility of the compound in the mobile phase. Therefore, racemic 1-6 were processed in a low number of cycles (Table 6), leading to enantiopure 1-6 in satisfactory amounts and yields, with an ee $\geq 95 \%$ (Table 6), as evidenced by analytical control of the collected fractions (Figure S1).

Table 6. (Semi-)preparative resolution of $(R / S)-\mathbf{1},(R / S)-\mathbf{2},(R / S)-\mathbf{3},(R / S)-\mathbf{5}$ on Chiralcel OJ-H $(10 \mathrm{~mm} \times 250 \mathrm{~mm}, \mathrm{dp}=5 \mu \mathrm{m})$ and of $(R / S)-4$ and $(R / S)-6$ on Chiralpak IA $(10 \mathrm{~mm} \times 250 \mathrm{~mm}$, $\mathrm{dp}=5 \mu \mathrm{m})$.

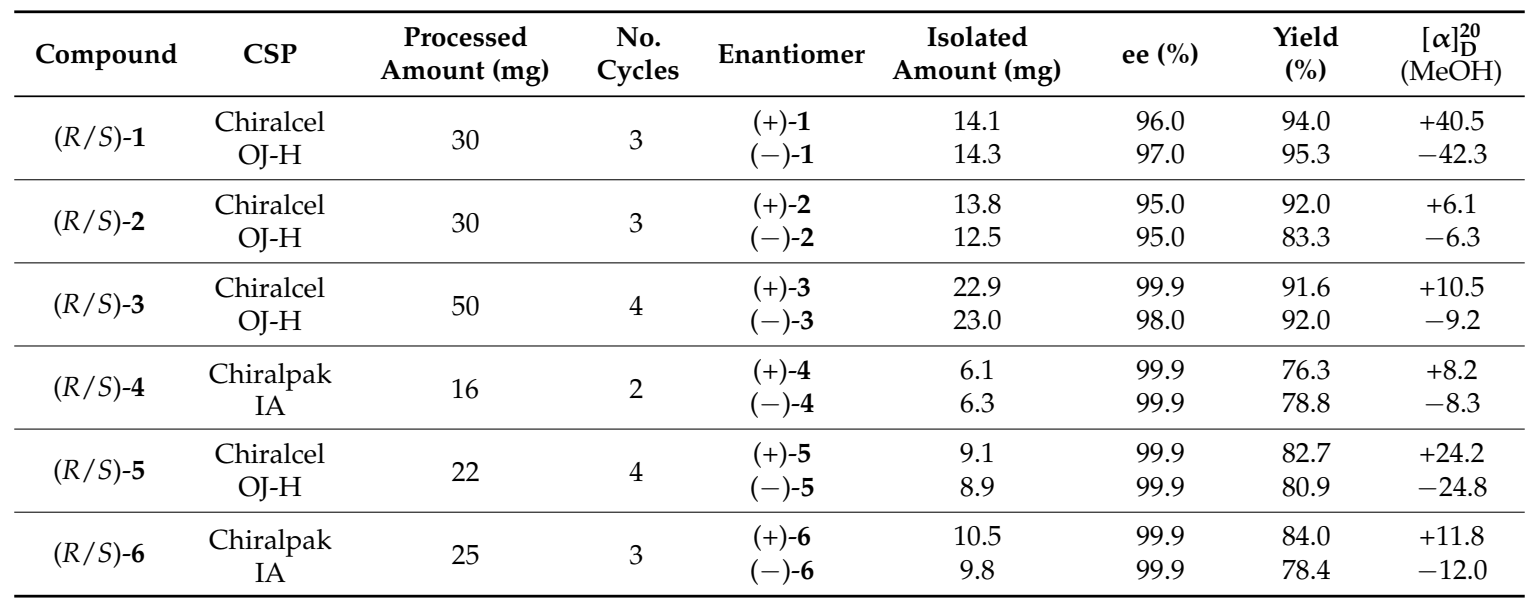

Flow rate: $2.5 \mathrm{~mL} / \mathrm{min}$. Detection: $254 \mathrm{~nm}$ (Compounds 1, 2, 5, 6) and $220 \mathrm{~nm}$ (Compounds 3, 4). Injection volume: $1.0 \mathrm{~mL}$.
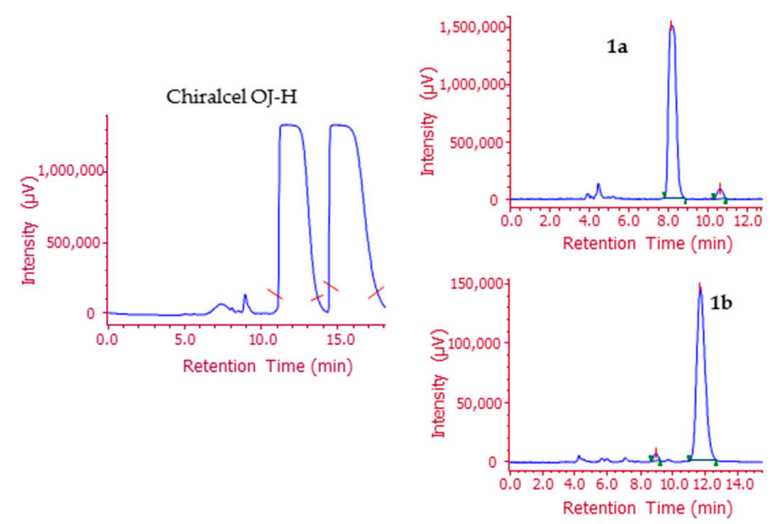

Figure 3. Representative chromatogram of (semi-)preparative resolution: compound $(R / S)$-1, Chiralcel OJ-H $(10 \mathrm{~mm} \times 250 \mathrm{~mm}, \mathrm{dp}=5 \mu \mathrm{m})$. Elution condition: 100\% EtOH, DEA 0.1\%, flow rate $2.5 \mathrm{~mL} / \mathrm{min}$. Injection volume $1.0 \mathrm{~mL}$. 1a: (+)-1, 1b: (-)-1. 
A representative example of (semi-)preparative resolution is reported in Figure 3. Actually, $30 \mathrm{mg}$ of racemic 1 were processed in three runs (45 min in total) at a flow rate of $2.5 \mathrm{~mL} / \mathrm{min}$ at room temperature. According to the chromatographic profile (Figure 3), a small intermediate fraction was collected. Final analysis of $\mathbf{1}$ enantiomers is shown in Figure 3.

\subsection{Absolute Configurational Assignment}

As the last step of this work, the absolute configuration at the stereogenic center of enantiomeric 1-6 was established by combining electronic circular dichroism (ECD) and chiral HPLC analysis. The electronic circular dichroism (ECD) spectra have been compared with the ECD curves of structural analogues RC-33 and RC-34, whose configuration was already assigned by us [13,14]. In detail, the ECD spectra of enantiomeric arylamino alcohols 1, 3 and 5 were compared with that of $(S)$-RC-34 (Figure 1) and the ECD spectra of enantiomeric 2, 4 and 6, with that of (S)-RC-33.

Briefly, comparable Cotton effects (CEs) for $(+)-\mathbf{1},(+)-\mathbf{3},(+)-\mathbf{5}$ and $(+)-(S)-\mathrm{RC}-34$ compounds are evident in two ranges of wavelengths. Between 195 and $207 \mathrm{~nm}$, there are negative CEs, and between 216 and $223 \mathrm{~nm}$ there are positive $C E$, attributable to ${ }^{1} L_{\mathrm{a}}$ and ${ }^{1} L_{\mathrm{b}}$ electronic transitions of benzene and naphthalene (Figure 4). The sign of the CEs of ${ }^{1} L_{\mathrm{a}}$ is consistently opposite that at the longer wavelength $\left({ }^{1} L_{\mathrm{b}}\right)$. Some evident differences in the profile of the curves are in agreement with the UV spectra and could depend on the substitution pattern of the aromatic moiety. Basing on these considerations, the (S) absolute configuration of (+)-(S)-RC-34 may be proposed also for (+)-1, (+)-3 and (+)-5, because the sequence around the stereogenic center is the same for all four compounds.

Further support to this configurational assignment was derived from the study of the elution order of chiral HPLC analysis, taking into account that the absolute configuration of structurally-related compounds usually follows the same chiral recognition mechanism in the chromatographic process on a given chiral stationary phase, using the same mobile phase. Accordingly, (S)-RC-34, (+)-1, (+)-3 and (+)-5 were analyzed under the same chromatographic conditions (Chiralcel OJ-H, 50\% $\mathrm{MeOH}$ and 50\% $\mathrm{EtOH}, 0.1 \%$ DEA) and resulted in all cases in the first eluted enantiomers. The elution order results confirmed that the $(S)$ absolute configuration may be attributed also to $(+)-\mathbf{1},(+)-\mathbf{3}$ and (+)-5.

Empirical absolute configuration assignment of 2, 4, 6 was effected applying a similar approach. ECD spectra of 2, 4, 6 have been compared with that of the structurally-related compound $(S)$-RC-33, as a reference of known stereochemistry. The enantiomers (+)-2,(+)-4, (+)-6 and (S)-RC-33 displayed a similar negative CE in the wavelength range between 198 and $230 \mathrm{~nm}$ and a CE between 214 and $255 \mathrm{~nm}$, associated with ${ }^{1} L_{\mathrm{a}}$ and ${ }^{1} L_{\mathrm{b}}$ electronic transitions of the aromatic chromophores, respectively. Again, the sign of the CEs of ${ }^{1} L_{\mathrm{a}}$ is consistently opposite that at the longer wavelength $\left({ }^{1} L_{\mathrm{b}}\right)$, and the differences in the profile of the curves could depend on the different aromatic nucleus. Based on these considerations, the $(S)$ absolute configuration of $(+)-(S)-R C-33$ may be proposed also for (+)-2, (+)-4 and (+)-6 (Figure 5), having the same substituents around the stereogenic center. Again, $(S)-R C-33$ and (+)-2 were analyzed under the same chromatographic conditions (Chiralcel OJ-H, $50 \% \mathrm{MeOH}$ and 50\% EtOH, 0.1\% DEA) and resulted in both cases in the first eluted enantiomers. Unfortunately, the OJ-H column is not able to solve Compounds 4 and $\mathbf{6}$. To confirm that a set of structurally-related compounds is characterized by the same absolute configuration, they must be analyzed under the same chromatographic conditions. Indeed, chiral recognition mechanisms on chiral stationary phases may be sensitive to even minor structural or conditional changes. Therefore, we took into consideration the chromatographic profiles of (S)-RC-33, (+)-2, (+)-4 and (+)-6 on Chiralpak IC (90/10 $n$-hep/IPA, 0.1\% DEA), a condition that ensures the baseline separation of all of the studied compound enantiomers. (S)-RC-33, (+)-2, (+)-4 and (+)-6 showed the same behaviors, confirming that all of the first eluted enantiomers are characterized by the same absolute configuration, that is the $(S)$ configuration. These results are in agreement with the data collected through ECD technique, and the $(S)$ absolute configuration may be attributed also to $(+)-\mathbf{1},(+)-\mathbf{3}$ and $(+)-\mathbf{5}$. 


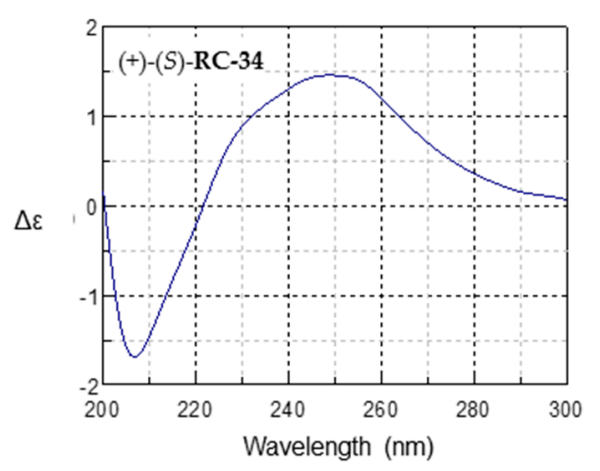

(A)

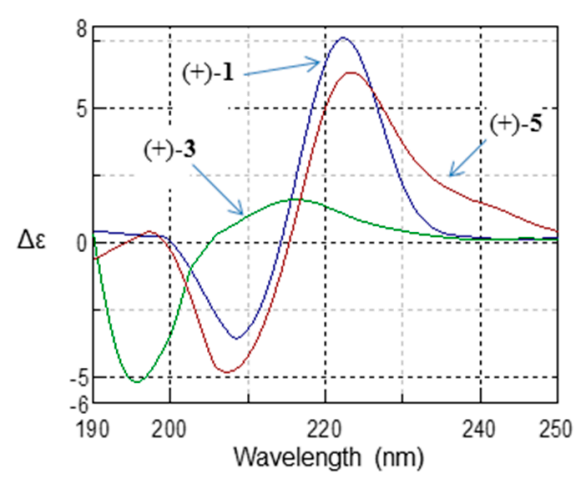

(B)

\begin{tabular}{ccccc}
\hline Compound & $\lambda_{\min }$ & $\Delta \varepsilon_{\min }$ & $\lambda_{\max }$ & $\Delta \varepsilon_{\max }$ \\
\hline$(S)-\mathrm{RC}-34$ & 206.5 & -2.78 & 253.0 & 1.09 \\
$(+)-\mathbf{1}$ & 208.5 & -3.58 & 222.5 & 7.59 \\
$(+)-3$ & 195.5 & -5.19 & 216.5 & 1.57 \\
$(+)-5$ & 207.5 & -4.82 & 223.5 & 6.31 \\
\hline
\end{tabular}

Figure 4. ECD curves of (A) (+)-(S)-RC-34 and (B) (+)-1, (+)-3, (+)-5 and their Cotton effect (CE) in the wavelength range 190-300 $\mathrm{nm}$.

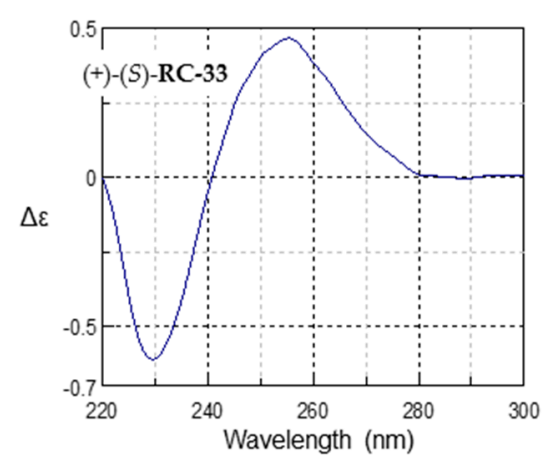

A

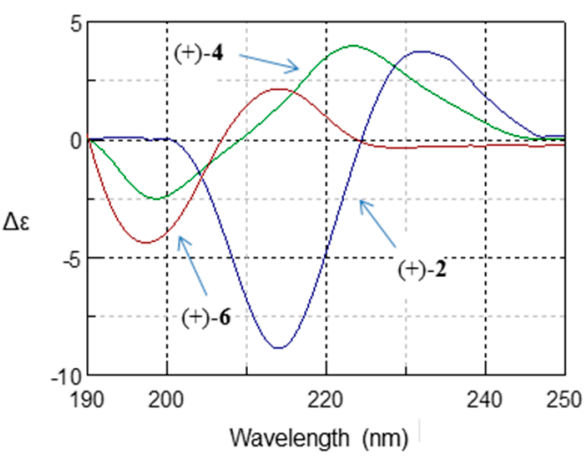

B

\begin{tabular}{ccccc}
\hline Compound & $\lambda_{\min }$ & $\Delta \varepsilon_{\min }$ & $\lambda_{\max }$ & $\Delta \varepsilon_{\max }$ \\
\hline$(S)-R C-33$ & 229.8 & -0.61 & 255.0 & 0.47 \\
$(+)-2$ & 214.0 & -9.04 & 232.5 & 3.56 \\
$(+)-4$ & 198.5 & -2.26 & 223.0 & 3.85 \\
$(+)-6$ & 198.0 & -4.34 & 214.0 & 2.18 \\
\hline
\end{tabular}

Figure 5. ECD curves of (A) (+)-(S)-RC-33, B) (+)-2, (+)-4, (+)-6 and their Cotton effect (CE) in the wavelength range of 190-300 $\mathrm{nm}$.

\section{Experimental Section}

\subsection{HPLC-UV Chiral Resolution}

In order to identify the best conditions to be properly scaled up to the (semi-)preparative scale, an analytical screening of cellulose- and amylose-based CSPs was firstly performed using Chiralcel OJ-H (Chiral technologies Europe, Illkirch-Cedex, France, Europe, $4.6 \mathrm{~mm}$ diameter $\times 150 \mathrm{~mm}$ length, dp $5 \mu \mathrm{m}$ ), Chiralpack IC (Chiral technologies Europe, Illkirch-Cedex, France, Europe, $4.6 \mathrm{~mm}$ diameter $\times 250 \mathrm{~mm}$ length, dp $5 \mu \mathrm{m}$ ) and Chiralpack IA (Chiral technologies Europe, Illkirch-Cedex, 
France, Europe, $4.6 \mathrm{~mm}$ diameter $\times 250 \mathrm{~mm}$ length, $\mathrm{dp} 5 \mu \mathrm{m}$ ) columns and eluting with a flow rate of $0.5 \mathrm{~mL} / \mathrm{min}, 1 \mathrm{~mL} / \mathrm{min}$ and $1 \mathrm{~mL} / \mathrm{min}$, respectively. Analytes were detected photometrically at 220 and $254 \mathrm{~nm}$. Unless otherwise specified, sample solutions were prepared dissolving analytes at $1 \mathrm{mg} / \mathrm{mL}$ in ethanol and filtered through $0.45-\mu \mathrm{m}$ PTFE membranes before analysis. The injection volume was $10 \mu \mathrm{L}$. The mobile phases consisted of alcohols (MeOH or/and $\mathrm{EtOH}$ ) or mixtures of $n$-hep and polar modifiers (EtOH or IPA). In all cases, $0.1 \%$ of DEA was added to the mobile phase. In the case of the Chiralpak IC columns, the analyses were carried out also in the presence of $0.3 \%$ of TFA. The retention factor $(k)$ was calculated using the equation $k=\left(t_{R}-t_{0}\right) / t_{0}$, where $t_{R}$ is the retention time and $t_{0}$ the dead time ( $t_{0}$ was considered to be equal to the peak of the solvent front and was taken from each particular run). The enantioselectivity $(\alpha)$ and the resolution factor (Rs) were calculated as follows: $\alpha=k_{2} / k_{1}$ and $\mathrm{Rs}=2\left(\mathrm{t}_{\mathrm{R} 2}-\mathrm{t}_{\mathrm{R} 1}\right) /\left(\mathrm{w}_{1}+\mathrm{w}_{2}\right)$, where $\mathrm{t}_{\mathrm{R} 2}$ and $\mathrm{t}_{\mathrm{R} 1}$ are the retention times of the second and the first eluted enantiomers and $\mathrm{w}_{1}$ and $\mathrm{w}_{2}$ are the corresponding base peak widths. The best conditions found by the screening protocol were applied to a (semi-)preparative scale-up. The enantiomers of 1, 2, 3 and 5 were then completely resolved by a (semi-)preparative process using a Chiralcel OJ-H column (10 mm diameter $\times 250 \mathrm{~mm}$ length, $5 \mu \mathrm{m}$ ), eluting with $\mathrm{EtOH}$ (for Compound 1) or $\mathrm{MeOH}$ (for Compounds 2, 3 and 5) at rt with a flow rate of $2.5 \mathrm{~mL} / \mathrm{min}$. Compounds 4 and 6 were resolved on Chiralpak IA (10 mm diameter $\times 250 \mathrm{~mm}$ length, $5 \mu \mathrm{m})$ using $\mathrm{MeOH}$ at a flow rate of $2.5 \mathrm{~mL} / \mathrm{min}$ as the eluent.

The eluate was fractioned according to the UV profile (detection at 220 and $254 \mathrm{~nm}$ ). The fractions obtained containing the enantiomers were evaporated at reduced pressure. Analytical control of the collected fractions was performed using the analytical columns.

\subsection{Electronic Circular Dichroism}

The solutions of 1-6 enantiomers: (+)-1 (c: $2.68 \times 10^{-5} \mathrm{M}$, in $n$-hexane), $(+)-\mathbf{2}\left(c: 1.90 \times 10^{-5} \mathrm{M}\right.$ in $n$-hexane), (+)-3 (c: $3.09 \times 10^{-5} \mathrm{M}$ in $n$-hexane), (+)-4 (c: $2.21 \times 10^{-5} \mathrm{M}$ in $n$-hexane), (+)-5 (c: $6.29 \times 10^{-6} \mathrm{M}$ in $n$-hexane), (+)-6 (c: $1.31 \times 10^{-5} \mathrm{M}$ in $n$-hexane; optical pathway $\left.1 \mathrm{~cm}\right),(+)-(S)-\mathrm{RC}-34$ (c: $2.5 \times 10^{-5} \mathrm{M}$ in $n$-hexane; optical pathway $1 \mathrm{~cm}$ ) and (+)-(S)-RC-33 (c: $9.12 \times 10^{-5} \mathrm{M}$ in $n$-hexane; optical pathway $1 \mathrm{~cm}$ ) were analyzed in a nitrogen atmosphere. ECD spectra were scanned at $50 \mathrm{~nm} / \mathrm{min}$ with a spectral band width of $2 \mathrm{~nm}$ and a data resolution of $0.5 \mathrm{~nm}$ (Figures 4 and 5).

\section{Conclusions}

In this paper, we presented the synthesis of the novel potential SR modulators 1-6 and their enantioseparation via HPLC chiral resolutions on cellulose- and amylose-based CSPs. A systematic screening protocol for enantioselective HPLC was established leading to fast and easy-to-use chiral HPLC separations suitable for a (semi-)preparative scale-up. The separation of the enantiomers was optimized by varying the chromatographic parameters. Baseline separations were obtained for all of the studied compounds under optimized chromatographic conditions. The recovery of the enantiomers after chromatography was in the range of $76 \%-95 \%$, for the individual enantiomers. (Semi-)preparative enantioselective chromatography for compounds of interest proves to be a straightforward, productive and robust methodology for the quick access to the desired amounts of pure enantiomers. It remains one of the most versatile and cost effective tools for the fast isolation of desired enantiomers from a racemic mixture. The absolute configuration at the chiral center of enantiomeric 1-6 was empirically assigned by combining electronic circular dichroism (ECD) and chiral HPLC analysis.

The bioactivity of each enantiomer is now under investigation in order to deeply understand the role of chirality in the SRs-ligand interaction.

Supplementary Materials: Supplementary materials can be accessed at: http:/ /www.mdpi.com/1420-3049/21/ 9/1210/s1.

Acknowledgments: The authors gratefully acknowledge Michela Culanti Indiano for the experimental support. 
Author Contributions: S.C. conceived of the work and contributed to reviewing the whole manuscript. She was also responsible for the correctness of all of the studies. M.R. and A.M. performed the research, analyzed the data and contributed to the writing of the manuscript. V.P provided guidance on the synthesis of the racemates. D.R. and M.J. provided guidance on the design of the screening and the up-scaling of the enantiomer separations.

Conflicts of Interest: The authors declare no conflict of interest.

\section{Abbreviations}

The following abbreviations are used in this manuscript:

$\begin{array}{ll}\text { MDPI } & \text { Multidisciplinary Digital Publishing Institute } \\ \text { DOAJ } & \text { Directory of Open Access Journals } \\ \text { DEA } & \text { Diethylamine } \\ \text { ECD } & \text { Electronic circular dichroism } \\ \text { EtOH } & \text { Ethanol } \\ \text { IPA } & \text { Isopropanol } \\ \text { MeOH } & \text { Methanol } \\ n \text {-hep } & n \text {-Heptane } \\ \text { TFA } & \text { Trifluoroacetic acid } \\ \text { UV } & \text { Ultraviolet }\end{array}$

\section{References}

1. Aydar, E.; Palmer, C.P.; Djamgoz, M.B. Sigma receptors and cancer: Possible involvement of ion channels. Cancer Res. 2004, 64, 5029-5035. [CrossRef] [PubMed]

2. Collina, S.; Gaggeri, R.; Marra, A.; Bassi, A.; Negrinotti, S.; Negri, F.; Rossi, D. Sigma receptor modulators: A patent review. Exp. Opin. Ther. Pat. 2013, 23, 597-613. [CrossRef] [PubMed]

3. Huang, Y.S.; Lu, H.L.; Zhang, L.J.; Wu, Z. Sigma-2 receptor ligands and their perspectives in cancer diagnosis and therapy. Med. Res. Rev. 2014, 34, 532-566. [CrossRef] [PubMed]

4. Wang, B.; Rouzier, R.; Albarracin, C.T.; Sahin, A.; Wagner, P.; Yang, Y.; Smith, T.L.; Meric Bernstam, F.; Marcelo, A.C.; Hortobagyi, G.N.; Pusztai, L. Expression of sigma 1 receptor in human breast cancer. Breast Cancer Res. Treat. 2004, 87, 205-214. [CrossRef] [PubMed]

5. Aydar, E.; Onganer, P.; Perrett, R.; Djamgoz, M.B.; Palmer, C.P. The expression and functional characterization of sigma (sigma) 1 receptors in breast cancer cell lines. Cancer Lett. 2006, 242, 245-257. [CrossRef] [PubMed]

6. Crottes, D.; Guizouarn, H.; Martin, P.; Borgese, F.; Soriani, O. The sigma-1 receptor: A regulator of cancer cell electrical plasticity? Front. Physiol. 2013, 4, 175. [CrossRef] [PubMed]

7. Megalizzi, V.; le Mercier, M.; Decaestecker, C. Sigma receptors and their ligands in cancer biology: Overview and new perspectives for cancer therapy. Med. Res. Rev. 2012, 32, 410-427. [CrossRef] [PubMed]

8. Collina, S.; Loddo, G.; Urbano, M.; Linati, L.; Callegari, A.; Ortuso, F.; Alcaro, S.; Laggner, C.; Langer, T.; Prezzavento, O.; et al. Design, synthesis, and SAR analysis of novel selective sigma1 ligands. Bioorg. Med. Chem. 2007, 15, 771-783. [CrossRef] [PubMed]

9. Rossi, D.; Urbano, M.; Pedrali, A.; Serra, M.; Zampieri, D.; Mamolo, M.G.; Laggner, C.; Zanette, C.; Florio, C.; Shepmann, D.; et al. Design, synthesis and SAR analysis of novel selective sigma1 ligands (Part 2). Bioorg. Med. Chem. 2010, 18, 1204-1212. [CrossRef] [PubMed]

10. Rossi, D.; Pedrali, A.; Urbano, M.; Gaggeri, R.; Serra, M.; Fernandez, L.; Fernandez, M.; Caballero, J.; Rosinsvalle, S.; Prezzavento, O.; et al. Identification of a potent and selective $\sigma 1$ receptor agonist potentiating NGF-induced neurite outgrowth in PC12 cells. Bioorg. Med. Chem. 2011, 19, 6210-6224. [CrossRef] [PubMed]

11. Rossi, D.; Marra, A.; Picconi, P.; Serra, M.; Catenacci, L.; Sorrenti, M.; Laurini, E.; Fermeglia, M.; Pricl, S.; Brambilla, S.; et al. Identification of RC-33 as a potent and selective $\sigma 1$ receptor agonist potentiating NGF-induced neurite outgrowth in PC12 cells. Part 2: G-scale synthesis, physicochemical characterization and in vitro metabolic stability. Bioorg. Med. Chem. 2013, 21, 2577-2586. [CrossRef] [PubMed]

12. Rossi, D.; Pedrali, A.; Gaggeri, R.; Marra, A.; Pignataro, L.; Laurini, E.; DalCol, V.; Fermeglia, M.; Pricl, S.; Schepmann, D.; et al. Chemical, pharmacological, and in vitro metabolic stability studies on enantiomerically pure RC-33 compounds: promising neuroprotective agents acting as $\sigma_{1}$ receptor agonists. Chem. Med. Chem. 2013, 8, 1514-1527. [CrossRef] [PubMed] 
13. Rossi, D.; Pedrali, A.; Marra, A.; Pignataro, L.; Schepmann, D.; Wünsch, B.; Ye, L.; Leuner, K.; Peviani, M.; Curti, D.; Azzolina, O.; Collina, S. Studies on the Enantiomers of as Neuroprotective Agents: Isolation, Configurational Assignment, and Preliminary Biological Profile. Chirality 2013, 25, 814-822. [CrossRef] [PubMed]

14. Rossi, D.; Marra, A.; Rui, M.; Laurini, E.; Fermeglia, M.; Pricl, S.; Schepmann, D.; Wuensch, B.; Peviani, M.; Curti, D.; et al. A step forward in the sigma enigma: A role for chirality in the sigma1 receptor-ligand interaction? MedChemComm 2014, 6, 138-146. [CrossRef]

15. Walker, J.M.; Bowen, W.D.; Walker, F.O.; Matsumoto, R.R.; De Costa, B.; Rice, K.C. Sigma receptors: Biology and function. Pharmacol. Rev. 1990, 42, 355-402. [PubMed]

16. Collina, S.; Loddo, G.; Urbano, M.; Rossi, D.; Mamolo, M.G.; Zampieri, D.; Alcaro, S.; Gallelli, A.; Azzolina, O. Enantioselective chromatography and absolute configuration of N,N-dimethyl-3-(naphthalen-2-yl)-butan1-amines: Potential Sigma1 ligands. Chirality. 2006, 18, 245-253. [CrossRef] [PubMed]

17. Rossi, D.; Nasti, R.; Marra, A.; Meneghini, S.; Mazzeo, G.; Longhi, G.; Memo, M.; Cosimelli, B.; Greco, G.; Novellino, E.; et al. Enantiomeric 4-Acylamino-6-alkyloxy-2 Alkylthiopyrimidines As Potential A3 Adenosine Receptor Antagonists: HPLC Chiral Resolution and Absolute Configuration Assignment by a Full Set of Chiroptical Spectroscopy. Chirality 2016. [CrossRef] [PubMed]

18. Gaggeri, R.; Rossi, D.; Collina, S.; Mannucci, B.; Baierl, M.; Juza, M. Quick development of an analytical enantioselective high performance liquid chromatography separation and preparative scale-up for the flavonoid Naringenin. J. Chromatogr. A 2011, 1218, 5414-5422. [CrossRef] [PubMed]

19. Rossi, D.; Marra, A.; Rui, M.; Brambilla, S.; Juza, M.; Collina, S. “Fit-for-purpose" development of analytical and (semi)preparative enantioselective high performance liquid and supercritical fluid chromatography for the access to a novel $\sigma 1$ receptor agonist. J. Pharm. Biomed. Anal. 2016, 118, 363-369. [CrossRef] [PubMed]

20. Pace, V.; Martínez, F.; Fernández, M.; Sinisterra, J.V.; Alcántara, A.R. Highly Efficient Synthesis of New $\alpha$-Arylamino- $\alpha$-chloropropan-2-ones via Oxidative Hydrolysis of Vinyl Chlorides Promoted by Calcium Hypochlorite. Adv. Synth. Catal. 2009, 351, 3199-3206. [CrossRef]

Sample Availability: Samples of all compounds are available from the authors.

(C) 2016 by the authors; licensee MDPI, Basel, Switzerland. This article is an open access article distributed under the terms and conditions of the Creative Commons Attribution (CC-BY) license (http://creativecommons.org/licenses/by/4.0/). 